\title{
A review of the changing patterns of suicide and deliberate self-harm in Sri Lanka
}

TN Rajapakse

\section{Abstract \\ Background}

In the mid 1990s, Sri Lanka had the second highest rate of suicide in the world, due to ingestion of pesticides. Since then, Sri Lanka has seen significant changes in the rates of suicide and self-harm by attempted or non-fatal self-poisoning.

\section{Aims}

The objective of this article is to examine the changes in rates and modes of suicide and attempted self-poisoning in Sri Lanka, from 1995 to the present, and discuss the significance of these changing patterns.

\section{Methods}

Electronic searches were carried out in Pubmed, using the following key words; suicide, deliberate self-harm, poisoning, attempted suicide and Sri Lanka.

\section{Results}

Since 1995 the rate of suicide in Sri Lanka has declined, with the annual suicide rate falling from
DOI: http://doi.org/10.4038/sljpsyc.v8i1.8132

47.0 per 100,000 in 1995 to 19.6 per 100,000 in 2009. Self-poisoning still remains the most common method of suicide, with a relatively small increase in suicide by other methods, such as hanging. But after 1995, there has been increased hospital admissions due to attempted self-poisoning, with more medication overdoses.

\section{Conclusion}

The fall in suicide rates in Sri Lanka is a positive outcome of preventive measures taken, including restriction of access to toxic pesticides. These need to be continued, together with increased focus on management of psychological contributory factors, such as depression and alcohol use disorders. At the same time, innovative and culturally appropriate preventive strategies are needed to address the increasing public health problem of attempted selfpoisoning.

SL J Psychiatry 2017; 8(1): 3-9

\section{Introduction}

In 1995, Sri Lanka claimed the dubious distinction of having the second highest suicide rate in the world. The most common method of suicide was by self-poisoning, most often by ingestion of pesticides, which carried a high case fatality (1). From a high of 47.0 per 100,000 in 1995, the rate of suicide in Sri Lanka has gradually declined to 14.58 per 100,000 in 2015 and in 2016 (2). Almost parallel to this drop in suicide rates, there have been reports of increasing numbers of hospital admissions for attempted or non-fatal self-poisoning (3). Thus since 1995, Sri Lanka has seen significant patterns of change in the rates of both suicide and selfharm; which is likely to have important lessons for health care planners.

This article examines changes in rates and modes of suicide and attempted self-harm by self-poisoning in Sri Lanka, from 1995 to the present, and discusses the significance of these changing patterns.

\section{Methodology}

Electronic searches were carried out in Pubmed, using the following key words; suicide, deliberate self-harm, poisoning, attempted suicide and Sri Lanka. Articles that reported rates and methods of suicide, attempted suicide and/or deliberate self-harm relevant to Sri Lanka, from 1995 to date, published in English language indexed journals, were included. Articles that focused on medical management of self-poisoning, and which did not differentiate between accidental and deliberate selfpoisoning, were excluded.

\section{Results}

The initial search resulted in 550 hits. After screening of abstracts, and exclusion of duplicates, 117 articles were retained (Figure 1). After examination of full text articles, based on inclusion and exclusion criteria 13 articles were included for the review (Table 1). 
Figure 1. Flow diagram for literature search.

Records identified through

Pubmed library database search using keywords: suicide, deliberate self-harm, poisoning, attempted suicide and Sri Lanka.

$$
(n=550)
$$

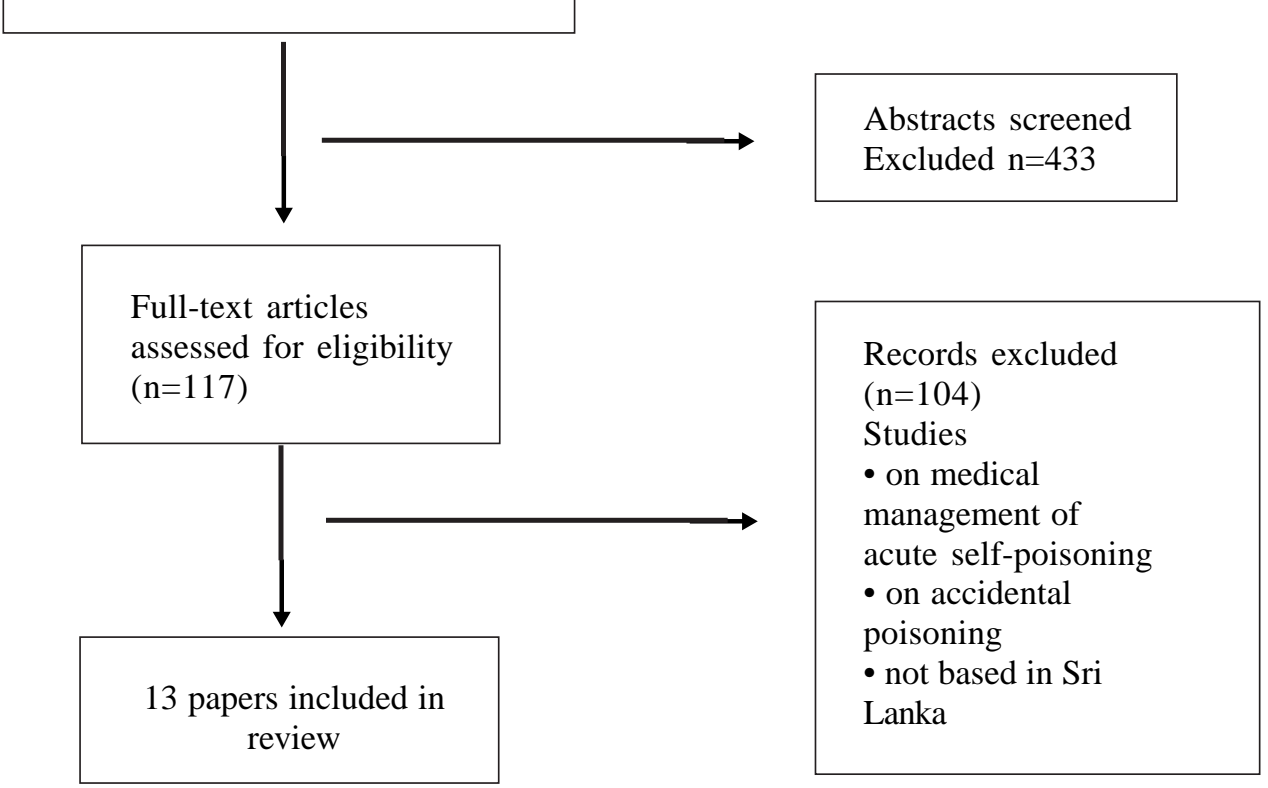

\begin{tabular}{|c|c|c|}
\hline & Title, and authors & Main outcomes of interest and findings \\
\hline 1 & $\begin{array}{l}\text { Regional variation in suicide rates in Sri Lanka } \\
\text { between } 1955 \text { and 2011: a spatial and temporal } \\
\text { analysis } \\
\text { Knipe DW, Padmanathan P, Muthuwatta L, } \\
\text { Metcalfe C, Gunnell D } \\
\text { BMC Public Health 2017; 17: } 193 \text { (4) }\end{array}$ & $\begin{array}{l}\text { Mapped district-level suicide rates for 1955, 1972, } 1980 \\
\text { and } 2011 \text { and investigated associations between district } \\
\text { level suicide rates and census-driven measures of rurality. } \\
\text { Found that increasing population density was inversely } \\
\text { associated with suicide rates, and this association was } \\
\text { strongest when pesticides were the most common method } \\
\text { of suicide (in 1980) compared to } 1950 \text {. }\end{array}$ \\
\hline 2 & $\begin{array}{l}\text { Suicide prevention through means restriction: } \\
\text { Impact of the } 2008-2011 \text { pesticide restrictions on } \\
\text { suicide in Sri Lanka } \\
\text { Knipe DW, Chang SS, Dawson A, Eddleston M, } \\
\text { Konradsen F, Metcalf C, Gunnell D. } \\
\text { Plos One DOI:10.1371/journal.pone.0172893 (5) }\end{array}$ & $\begin{array}{l}\text { Age-standardised overall, sex-specific, and method-specific } \\
\text { suicide rates were calculated using data from } \\
\text { the Sri Lankan police data (1989-2015). } \\
\text { Overall suicide mortality dropped by } 21 \% \text { between } 2011 \\
\text { and } 2015 \text {, from } 18.3 \text { to } 14.3 \text { per } 100,000 \text {. There was a large } \\
\text { decline in suicides due to pesticide ingestion, during this } \\
\text { period. }\end{array}$ \\
\hline 3 & $\begin{array}{l}\text { From pesticides to medicinal drugs: time series } \\
\text { analyses of methods of self-harm in Sri Lanka } \\
\text { de Silva VA, Senanayake SM, Dias P, Hanwella R. } \\
\text { Bull World Health Organ 2012; 90: 40-46 (2) }\end{array}$ & $\begin{array}{l}\text { Time series analysis of suicide rates and incidence } \\
\text { of hospital admissions due to ingestion of different } \\
\text { types of poison, from } 1995-2009 \text {. } \\
\text { Between } 1996-2008 \text {, the annual incidence of hospital } \\
\text { admissions due to poisoning by a medicinal or biological } \\
\text { substance increased exponentially from } 48.2 \text { to } 115.4 \\
\text { admissions per } 100,000 \text { population. The annual incidence } \\
\text { of suicide decreased exponentially from } 47.0 \text { per } 100,000 \\
\text { in } 1995 \text { to } 19.6 \text { per } 100,000 \text { in } 2009 \text {. }\end{array}$ \\
\hline
\end{tabular}




\begin{tabular}{|c|c|c|}
\hline & Title, and authors & Main outcomes of interest and findings \\
\hline 4 & $\begin{array}{l}\text { Comparison of suicide rates in Sri Lanka during } \\
\text { and after the civil war } \\
\text { Rodrigo A, Owada K, Wainer J, Baker R, and } \\
\text { Williams S } \\
\text { Australasian Psychiatry 2013; } 21: 410 \text { (7) }\end{array}$ & $\begin{array}{l}\text { Compared suicide rates, methods and demographics in } \\
\text { Sri Lanka in the last two years of the civil war and in } \\
\text { the subsequent two years of post-war period, based } \\
\text { on data from the Sri Lanka Police. } \\
\text { Describes a significant reduction in suicide rates } \\
\text { between these two periods, with a total reduction } \\
\text { of } 8 \%\end{array}$ \\
\hline 5 & $\begin{array}{l}\text { Impact of pesticide regulations on suicide in } \\
\text { Sri Lanka } \\
\text { Gunnell D, Fernando R, Hewagama M, Priyangika WDD, } \\
\text { Konradsen F, } \\
\text { Eddleston M. International Journal of Epidemiology } \\
\text { 2007; 36: 1235-1242 (8) }\end{array}$ & $\begin{array}{l}\text { Ecological analysis of trends in suicide and risk factors } \\
\text { for suicide in Sri Lanka, 1975-2005. } \\
\text { Suicide rates in Sri Lanka increased in the 1970s and } \\
80 \text { s, and reached a peak in 1995; and thereafter } \\
\text { have fallen. } \\
\text { The fall in suicide rates was associated with ban class I } \\
\text { pesticides methamidophos and monocrotophos (1995) } \\
\text { and class II pesticide endosulfan (1988). } \\
\text { Authors did not find significant association with other } \\
\text { factors, including the period of the civil war. }\end{array}$ \\
\hline 6 & $\begin{array}{l}\text { Suicide in Sri Lanka 1975-2012: age, period and } \\
\text { cohort analysis of police and hospital data } \\
\text { Knipe DW, Metcalf C, Fernando R, Pearson M, } \\
\text { Konradsen F, Eddleston M, Gunnell M } \\
\text { BMC Public Health 2014; } 14: 839 \text { (6) }\end{array}$ & $\begin{array}{l}\text { Examined secular trends of suicide in Sri Lanka } \\
\text { (from 1975-2012), based on police and hospital data. } \\
\text { Reports changes in age and gender patterns of suicide } \\
\text { since the 1980s. }\end{array}$ \\
\hline 7 & $\begin{array}{l}\text { A descriptive study of self-poisoning in Ampara } \\
\text { Rajasuriya M, Asanthi MAl, Ranaweera N } \\
\text { Ceylon Medical Journal 2012; 57: } 50 \text { (15) }\end{array}$ & $\begin{array}{l}\text { Examined admissions to hospitals in Ampara after self- } \\
\text { poisoning, during } 3 \text { months (in 2009). Included } 230 \text { admissions, } \\
\text { with a rate of self-poisoning of } 406 \text { per } 100,000 \text { per year }\end{array}$ \\
\hline 8 & $\begin{array}{l}\text { Analysis of } 8000 \text { hospital admissions for acute } \\
\text { poisoning in a rural area in Sri Lanka } \\
\text { Van der Hoek W, Konradsen F } \\
\text { Clin Toxicol 2006; 44(3): } 225-31 \text { (13) }\end{array}$ & $\begin{array}{l}\text { Examined incidence of acute poisoning, based on } \\
\text { retrospective examination of hospital records of six } \\
\text { hospitals in southern Sri Lanka from 1990-2002. } \\
\text { Average incidence of poisoning over the study period } \\
\text { was } 318 / 100,000 \text {. }\end{array}$ \\
\hline 9 & $\begin{array}{l}\text { Demographic risk factors in pesticide related } \\
\text { suicides in Sri Lanka; research letter. } \\
\text { Desapriya EBR, Joshi P, Han G, Rajabali F } \\
\text { Injury Prevention 2004; 10: 125-127 (12) }\end{array}$ & $\begin{array}{l}\text { Examined pesticide related deaths in } 2002 \text { in Sri Lanka, } \\
\text { based on data extracted from the Department of Police } \\
\text { in Colombo, Sri Lanka, and population health data from } \\
\text { the Ministry of Health. } \\
\text { For 2002: Age standardised rates showed differences } \\
\text { in pesticide related suicides by age and gender; males } \\
\text { had higher pesticide related suicide mortality risk than } \\
\text { females. In } 2002 \text {, among males, suicide rates peaked } \\
\text { between } 60-64 \text { years. }\end{array}$ \\
\hline 10 & $\begin{array}{l}\text { Geographical variation in admissions due to } \\
\text { poisoning in Sri Lanka: a time series analysis } \\
\text { Hanwella R, Senanayake SM, de Silva VA } \\
\text { Ceylon Medical Journal 2012; } 57: 152-158 \text { (3) }\end{array}$ & $\begin{array}{l}\text { Examined time trends in suicide and self-poisoning } \\
\text { from 1995-2008, based on data from the Ministry } \\
\text { of Health, Sri Lanka. } \\
\text { All districts except Kilinochchi and Mullativu showed } \\
\text { an increase in rates of admissions due to poisoning } \\
\text { with drugs, medicaments and biological substances. }\end{array}$ \\
\hline
\end{tabular}




\begin{tabular}{|c|c|c|}
\hline & Title, and authors & Main outcomes of interest and findings \\
\hline 11 & $\begin{array}{l}\text { Self-poisoning in rural Sri Lanka: small-area } \\
\text { variations in incidence } \\
\text { Manuel C, Gunnell DJ, van der Hoek W, Dawson A, } \\
\text { Wijeratne IK, Konradsen F } \\
\text { BMC Public Health 2008; 8: } 26 \text { (14) }\end{array}$ & $\begin{array}{l}\text { Ecological analysis of intentional self-poisoning } \\
\text { in a rural area of Sri Lanka (Hambanthoata) in } 2002 \text {. } \\
\text { The overall incidence of self-poisoning in these } \\
\text { areas in } 2002 \text { was } 315 \text { per } 100,000 \text {. }\end{array}$ \\
\hline 12 & $\begin{array}{l}\text { Repetition of suicide attempts Bertolote et al } \\
\text { Crisis 2010; 31(4): 194-201 (16) }\end{array}$ & $\begin{array}{l}\text { Data from emergency care settings in five culturally } \\
\text { different low and middle income countries participating } \\
\text { in the WHO SUPRE-MISS study } \\
\text { Repetition of self-harm at } 18 \text { months follow-up in Colombo } \\
\text { was } 4 \% \text {. }\end{array}$ \\
\hline 13 & $\begin{array}{l}\text { Repetition rate after non-fatal self-poisoning in Sri } \\
\text { Lanka: a one year prospective longitudinal study. } \\
\text { Rajapakse TN, Griffiths KM, Cotton S, Christensen H. } \\
\text { Ceylon Medical Journal 2016; } 61: 154-158 \text { (17) }\end{array}$ & $\begin{array}{l}\text { Persons admitted to hospital for medical management of } \\
\text { attempted self-poisoning were reassessed after one year. } \\
\text { Repetition of self-harm (by any method) at } 12 \text { month } \\
\text { follow-up was } 2.5 \% \text {. }\end{array}$ \\
\hline
\end{tabular}

\section{Rates of suicide}

Six studies included in the review commented on the rates of suicides in Sri Lanka since 1995 (2,4-8). A common theme reported in all six articles was the decline of overall suicide rates in Sri Lanka during the past two decades. De Silva et al reported that the annual suicide rate had reduced from 47.0 per 100,000 in 1995 to 19.6 per 100,000 in 2009 , with an absolute reduction of 27.4 suicides per 100,000 (2). A time trend analysis of the suicide rate showed an exponential decline; the trend was $Y_{t}=41.61 \times 0,947^{t}$ where $Y_{t}$ was the annual incidence of suicide and $t$ was the time elapsed (2).

\section{Suicide rates by age and gender}

Knipe et al examined the rates of suicide in Sri Lanka by age and gender; and reported that similar to the overall patterns of suicide, among males there has been a rapid decline in all age-specific suicide rates since 1995 onwards (6). In the mid-1980s suicide rates among males were higher in the 17-25 year age group than among older males (aged >35 years), but since 1999 this has changed, with the risk of suicide in males increasing with age (6).

Similar to suicide rates in the males, among females too there has been a linear decline in suicide rates across all ages, since 1995 to 2011 (9). However in contrast to the males, throughout the past three decades, among females, suicide rates have remained highest among younger females ( $<35$ years) compared to older females. This difference in female suicide rates between the youngest and oldest age groups was most marked in the pre-1987 era (upto a 5 fold difference); and despite the decline in overall female suicide rates, the higher rates among younger females has persisted $(6,10)$. For instance, by 2011, among females, the highest suicide rate was in the 20-29 year age group (13.98/100,000); while the lowest rate was seen in the 40-49 year age group $(5.29 / 100,000)(9)$.

\section{Comparison of suicide rates among males and females}

In keeping with patterns of suicide internationally, the rate of suicide in Sri Lanka during the period 1995 to 2016 was higher among males than that in females $(9,11,12)$. The reported suicide rate among males was 2.92 times that of females in 1995; by 2011 the rate in males was 3.77 times that of females (9). When age specific suicide rates were compared, higher suicide rates were seen in males in all age groups except the youngest age group (10-19 years); in this 10-19 year age group category the rate of suicide in females is slightly higher compared to males (9).

\section{Modes of suicide}

Overall to date, the most common method of suicide in Sri Lanka has been by self-poisoning, most often by pesticide ingestion (6). This despite the fact that from 1995 onwards, rates of suicides by self-poisoning have declined in both genders; the rate of suicide by selfpoisoning fell from 42/100,000 (79\% of all suicides) in $1994-96$ to $11 / 100,000$ (48\% of all suicides) in by 2010-2012 (2,6). The second most common method of suicide has been hanging; this has shown some increase among both genders - from an overall rate of $3 / 100,000$ in $1975-77$ (13\% of all suicides) to $8 / 100,000$ in $2010-12$ (36\% of all suicides) (6). 


\section{Trends in attempted or non-fatal self- poisoning}

Almost all studies on non-fatal self-harm in Sri Lanka have been carried out based on examination of those admitted to hospital due to attempted or non-fatal selfpoisoning (Table 1). Data on other methods of self-harm are minimal. Nine studies included in this review commented on non-fatal self-poisoning in Sri Lanka. Reported rates of hospital admissions for selfpoisoning included 315/100,000 in 2002 (in Southern Sri Lanka), an average of 318/100,000 from 1992-2002 (again in Southern Sri Lanka) and 406/100,000 from Ampara, for three months in 2009 (13-15).

Three studies had examined changes in rates of hospital admissions for self-poisoning with time $(2,3,13)$. The common theme reported was an increasing rate of hospital admissions for self-poisoning, characterised by increased ingestion of drugs, medicaments and other biological substances. Hanwella et al, reported that all districts in Sri Lanka, except for Killinochchi and Mullativu, had increased rates of hospital admissions due to ingestion of drugs, medicaments and other biological substances, from 1995-2008 (3). They also noted a decrease in admissions due to pesticide poisoning across time, which was seen in both urban and more rural agricultural districts (3). There is a reported exponential increase in the rate of admissions for self-poisoning from 1995 to 2008, from 204.8 admissions per 100,000 population in 1995 , to 321.2 per 100,000 in 2007 (2).

\section{Repetition risk after self-harm}

Data on rates of repetition of self-harm in Sri Lanka is limited; two studies in this review prospectively examined the rates of repetition following non-fatal self-poisoning, and reported repetition rates of $4 \%$ and $2.7 \%$ at 18 month and 12 month follow-up, respectively $(16,17)$.

\section{Discussion}

Since 1995 onwards the suicide rates in Sri Lanka show a significant decline, in both genders, and across all age groups. Measures taken to restrict access of toxic pesticides in Sri Lanka, from the mid 1990s onwards appears to be one of the most significant factors contributing to this drop in rate of suicides $(5,8)$. It is notable that pesticide poisoning has continued to decline after the turn of the century, though no major restrictions to pesticide availability have been applied. This may be due to the ongoing shift towards increasing use of medication overdoses, with it's lower associated case fatality (2). Other factors, such as improved and more accessible medical care following poisoning, may also have contributed to the overall fall in suicide rates. It has been suggested that the period of the civil war may have affected suicide rates, but overall evidence is inconclusive $(7,8,18)$.
Reduction of suicide rates by restriction of a particular mode of suicide, does give rise to the possibility of method substitution - or the increase of suicide by adoption of different methods. In keeping with this, the rates of suicide in Sri Lanka by hanging have increased from $13 \%$ in $1975-77$ to $36 \%$ of all suicides in $2010-12$ (6). However this increase in rates of hanging over the past decades has been much less than the fall in rates of suicides due to pesticide ingestion $(5,6)$. Thus overall Sri Lanka can report a success story with regards to the reduction of rates of suicide by means restriction, which has important implications for future policy makers $(8,19)$. However, we still need to be aware of the possible increase of suicide rates in future by other methods such as hanging, and to monitor for possible emergence of this phenomenon.

Overall rates of suicide in Sri Lanka throughout the past decades has been more among males than females, which is in keeping with patterns of suicide throughout the world (11). However a key finding is that when considering the younger age group (10-19 years), rates of suicide in Sri Lanka are higher among females than males $(9,10)$. And while the risk of suicide among males in Sri Lanka is now associated with increased age, the rates of suicide in females still remain highest among the younger age groups (6). Similar patterns of female suicides have been reported in other South Asian countries, and in the past, from China $(20,21)$. This suggests that restriction alone is not enough to address the issue of young female suicides in this country. There is a need to examine the gender specific socio-cultural as well psychological factors that maybe contributing to this phenomenon in Sri Lanka (10).

Although the suicide rates have declined since 1995, the rates of hospital admissions for attempted or nonfatal self-poisoning in Sri Lanka have increased (2). This appears to represent a true increase, though other factors, such as reduced lethality of substances ingested, and greater accessibility of hospital services in recent years, may also influence these findings.

Since the mid-1990s, patterns of non-fatal self-harm have shifted to resemble patterns seen in the West, with increasing medicinal overdoses, and higher rates of nonfatal self-poisoning in young females compared to males $(2,22)$. The high rate of hospital admissions due to non-fatal poisoning by medication and other biological substances has now become an important public health challenge, associated with significant individual distress as well economic cost to the country (23).

Interpersonal conflict is a commonly reported proximal trigger which appears to precipitate the act of non-fatal self-poisoning; similar coping patterns have been described from other countries in South-Asia (24-26). Difficulty in tolerating acute emotional distress associated with interpersonal conflict, feelings of shame, and distress, and patterns of learnt behaviour against a 
background of socio-economic difficulties, may contribute towards this self-harm behaviour (24). Depression and alcohol use disorders also play a significant role, especially with regards to non-fatal self-poisoning behaviour in older males $(27,28)$.

In Sri Lanka, the reported rate of repetition following an attempt of self poisoning, is lower than rates of repetition reported from the West (29). However similar low rates of repetition have been reported from other parts of Asia $(29,30)$. Further research is needed to explore whether this is indeed a true difference, and possible contributory factors.

\section{Limitations}

This review was limited to English language articles published in indexed journals listed in Pubmed, and there was no search of the grey literature; this may have led to the inadvertent omission of relevant articles, although every effort was made to minimise this by searching bibliographies of the articles included. Many articles included in the review based their findings on data from the Sri Lanka Police and the Ministry of Health, and any inaccuracies in the original data may also have biased the findings.

\section{Conclusions}

The fall in rates of suicide over the past two decades, is a very positive and important outcome of measures taken to reduce suicide, including restriction of access to toxic pesticides. These measures need to be continued, while monitoring for increase of suicide rates by other methods, such as by hanging. There is now also a need to focus on other psychological factors influencing suicide and self-harm - such as increased awareness and management of depression and alcohol use disorders. The increased occurrence of suicide among older males and younger females should also be areas of future focus.

On the other hand, rates of attempted or non-fatal selfpoisoning appear to be increasing, with a shift towards Western patterns of more medicinal overdoses; now a key public health problem. Exploration of innovative and culturally appropriate preventive strategies is needed to address this issue.

\section{Conflicts of interest}

None declared

TN Rajapakse, Department of Psychiatry, Faculty of Medicine, University of Peradeniya

Corresponding author: TN Rajapakse

Email: gemba471@gmail.com

http://orcid.org/0000-0001-9732-4666.

\section{References}

1. Eddleston M, Gunnell D, Karunaratne A, de Silva D, Shefiff MH, Buckley NA. Epidemiology of intentional selfpoisoning in rural Sri Lanka. Br J Psychiatry 2005; 187: 583-4.

2. de Silva VA, Senanayake SM, Dias P, Hanwella R. From pesticides to medicinal drugs: time series analyses of methods of self-harm in Sri Lanka. Bull World Health Organ 2012; 90(1): 40-6.

3. Hanwella R, Senanayake SM, De Silva VA. Geographical variation in admissions due to poisoning in Sri Lanka: a time series analysis. Ceylon Med J 2012; 57(4): 152-8.

4. Knipe DW, Padmanathan P, Muthuwatta L, Metcalfe C, Gunnell D. Regional variation in suicide rates in Sri Lanka between 1955 and 2011: a spatial and temporal analysis. BMC Public Health 2017; 17(1): 193.

5. Knipe DW, Chang S-S, Dawson A, Eddleston M, Konradsen F, Metcalfe C, et al. Suicide prevention through means restriction: Impact of the 2008-2011 pesticide restrictions on suicide in Sri Lanka. PLoS One 2017; 12(3): e0172893.

6. Knipe DW, Metcalfe C, Fernando R, et al. Suicide in Sri Lanka 1975-2012: age, period and cohort analysis of police and hospital data. BMC Public Health 2014; 14: 839.

7. Rodrigo A, Owada K, Wainer J, Baker R, Williams S. Comparison of suicide rates in Sri Lanka during and after the civil war. Australas Psychiatry 2013; 21(4): 410.

8. Gunnell D, Fernando R, Hewagama M, Priyangika WDD, Konradsen F, Eddleston M. The impact of pesticide regulations on suicide in Sri Lanka. Int J Epidemiol 2007; 36(6): 1235-42.

9. de Silva V, Hanwella R, Senanayake M. Age and sex specific suicide rates in Sri Lanka from 1995-2011. SL J Psychiatry 2012; 3(2): 7-11.

10. Rajapakse TN, Tennakoon SUB. Gender differences in suicide in Sri Lanka - what does it tell us? Ceylon Med J 2016; 61: 139-41.

11. Värnik P. Suicide in the World. Int J Environ Res Public Health 2012; 9(3): 760-71.

12. Desapriya EBR, Joshi P, Han G, Rajabali F. Demographic risk factors in pesticide related suicides in Sri Lanka. Inj Prev 2004; 10(2): 125-7. 13.

13. van der Hoek W. Analysis of 8000 Hospital Admissions for Acute Poisoning in a Rural Area of Sri Lanka. Clin Toxicol (Phila) 2006; 44(3): 225-31.

14. Manuel C, Gunnell DJ, van der Hoek W, Dawson A, Wijeratne IK, Konradsen F. Selfpoisoning in rural Sri Lanka: small-area variations in incidence. BMC Public Health 2008; 8: 26.

15. Rajasuriya M, Asanthi MAI, Ranaweera N. A descriptive study on self-poisoning in Ampara. Ceylon Med J 2012; 57(1): 50

16. Bertolote JM, Fleischmann A, De Leo D, et al. Repetition of Suicide Attempts. Crisis 2010; 31(4): 194-201.

17. Rajapakse T, Griffiths KM, Cotton S, Christensen H. Repetition rate after non-fatal self-poisoning in Sri-Lanka: a one year prospective longitudinal study. Ceylon Med J 2016; 61: 154-8. 
18. Somasundaram DJ, Rajadurai S. War and suicide in northern Sri Lanka. Acta Psychiatr Scand 1995; 91: 1-4.

19. Gunnell D, Eddleston M, Phillips MR, Konradsen F. The global distribution of fatal pesticide self-poisoning: Systematic review. BMC Public Health 2007; 7: 357.

20. Phillips MR, Li X, Zhang Y. Suicide rates in China, 199599. Lancet 2002; 359(9309): 835-40.

21. Adityanjee D. Suicide Attempts and Suicides in India: CrossCultural Aspects. Int J Soc Psychiatry 1986; 32(2): 64-73.

22. Rajapakse T, Griffiths KM, Christensen H. Characteristics of non-fatal self-poisoning in Sri Lanka: a systematic review. BMC Public Health 2013; 13: 331.

23. Wickramasinghe K. Cost to government health-care services of treating acute selfpoisonings in a rural district in Sri Lanka. Bull World Health Organ 2009; 87: 180-85.

24. Rajapakse T, Griffiths KM, Christensen H, Cotton S. Nonfatal self-poisoning in Sri Lanka: associated triggers and motivations BMC Public Health 2015; 15: 1167.

25. Parkar SR, Dawani V, Weiss MG. Clinical Diagnostic and Sociocultural Dimensions of Deliberate Self-Harm in
Mumbai, India. Suicide Life Threat Behav 2006; 36(2): 223-38.

26. Khan MM, Islam S, Kundi AK. Parasuicide in Pakistan: experience at a university hospital. Acta Psychiatr Scand 1996: 93: 264-67.

27. Rajapakse T, Christensen H, Cotton S, Griffiths KM. Nonfatal self-poisoning across age groups, in Sri Lanka. Asian J Psychiatr 2016; 19: 79-84.

28. Jayasinghe NRM, Foster JH. Deliberate Self-Harm/ Poisoning, Suicide Trends. The Link to Increased Alcohol Consumption in Sri Lanka. Arch Suicide Res 2011; 15(3): 223-37.

29. Owens D,Horrocks J,House A. Fatal and non-fatal repetition of self-harm: Systematic review. Br J Psychiatry 2002; 181: 193-9.

30. Carroll R, Metcalfe C, Gunnell D. Hospital Presenting SelfHarm and Risk of Fatal and Non-Fatal Repetition: Systematic Review and Meta-Analysis. PLoS One 2014; 9(2): p. e89944. 